\title{
Electronic commerce impact on the circulation of agricultural products and countermeasures
}

\author{
Lihong Cai ${ }^{1, a^{*}}$ \\ ${ }^{1}$ Luoyang Normal University Business School, Luoyang, Henan, 471000, China \\ aemail: mingtang_ty@126.com
}

Keywords:Agricultural products; E-business; Development status; Suggestions

\begin{abstract}
In this paper, a review of a large number of domestic and foreign research literature on agricultural development status of e-commerce at home and abroad were analyzed and compared; combed agricultural development in e-commerce course; summarize the e-commerce in China's major agricultural business model using the Fifth; summed up China's agricultural e-commerce made in the presence of the main problems and their causes, such as: many obstacles in our rural areas to promote agricultural e-commerce restrictions imposed, agricultural e-commerce services facing agricultural e-commerce logistics links encountered some bottlenecks, any natural agricultural food safety is a prominent problem to be solved; also proposed to solve the above problems related suggestions, such as: how to actively guide farmers voluntarily to put up the construction of agricultural e-commerce systems, how to establish a sound system service system, how to accelerate the construction of agricultural infrastructure of logistics, how to establish and improve agricultural standardization system specification and traceability systems.
\end{abstract}

\section{Introduction}

Agricultural products are essential to the lives of the people the most basic protection, the situation is closely related to the supply of agricultural products and stability and economic development of society [1-3]. With the advent of the Internet era of rapid development of information technology, the traditional agricultural products sales model is facing a huge challenge [4]. The only way for the development of agriculture is the industrialization of agriculture, in the storm of today's information age, e-commerce this new agricultural model in front of the public [5,6]. As an effective carrier of agricultural industrialization, give full play to the industrialization of agriculture business advantage. Agricultural e-commerce information platform, carrying three from low to high service functions, one of its most basic function, which provides an information exchange, online payment, logistics sales activities: Second Intermediate function, it can provide financial analysis, market research, production plan of a number of commercial activities; and finally advanced features, it is strongly driven by the agricultural industry sales subsidiary and associated advances (finance, transport, communications) services industry. So that the overall level of China's agricultural industry get a higher increase [7-10].

In recent years, with the gradual penetration of the market economy in agriculture, more and more e-commerce and agricultural extension people who realize that agricultural e-commerce is already an interdisciplinary, cross-cutting, promote agricultural industrialization effective way. At present, the rapid development of related industrial chain of sales of agricultural products, electronic information, supporting logistics and warehousing services, financial services, have caused great concern in the government sector, related scholars and practitioners in all aspects. E-commerce is an agricultural holding agricultural producers, the other end connected to an e-commerce enterprises, agricultural production enterprises to build brands, while e-commerce businesses have created their own unique brand, strict control of production to the source, also for electricity supplier's business model and the industry is a major test of conscience $[11,12]$.

In this paper, a review of a large number of domestic and foreign research literature on agricultural development status of e-commerce at home and abroad were analyzed and compared; combed agricultural development in China e-commerce course; summarize the e-commerce in China's major 
agricultural business model using the fifth; summed up China's agricultural e-commerce made in the presence of the main problems and their causes, such as: many obstacles in our rural areas to promote agricultural e-commerce restrictions imposed, agricultural e-commerce services facing agricultural e-commerce logistics links encountered some bottlenecks, any natural agricultural food safety is a prominent problem to be solved; also proposed to solve the above problems related suggestions, such as: how to actively guide farmers voluntarily to put up the construction of agricultural e-commerce systems, how to establish a sound system service system, how to accelerate the construction of agricultural infrastructure of logistics, how to establish and improve agricultural standardization system specification and traceability systems.

\section{Product modern business model}

2.1 International comparison of modern agricultural products logistics

Foreign economic development faster, their agricultural products logistics industry development earlier, agricultural logistics development, especially in developed countries is even more advanced. In this paper, the United States as a typical example of comparative analysis of modern agriculture and logistics [13]. China's "small farmers, big market" such special agricultural production patterns so that the source of most agricultural producers had to face alone the huge market demand, but the US market, showing a more social service system, complete system construction, the US agricultural products more smooth and efficient logistics. Here on China and the United States made a logistics system Figure 1 compare:

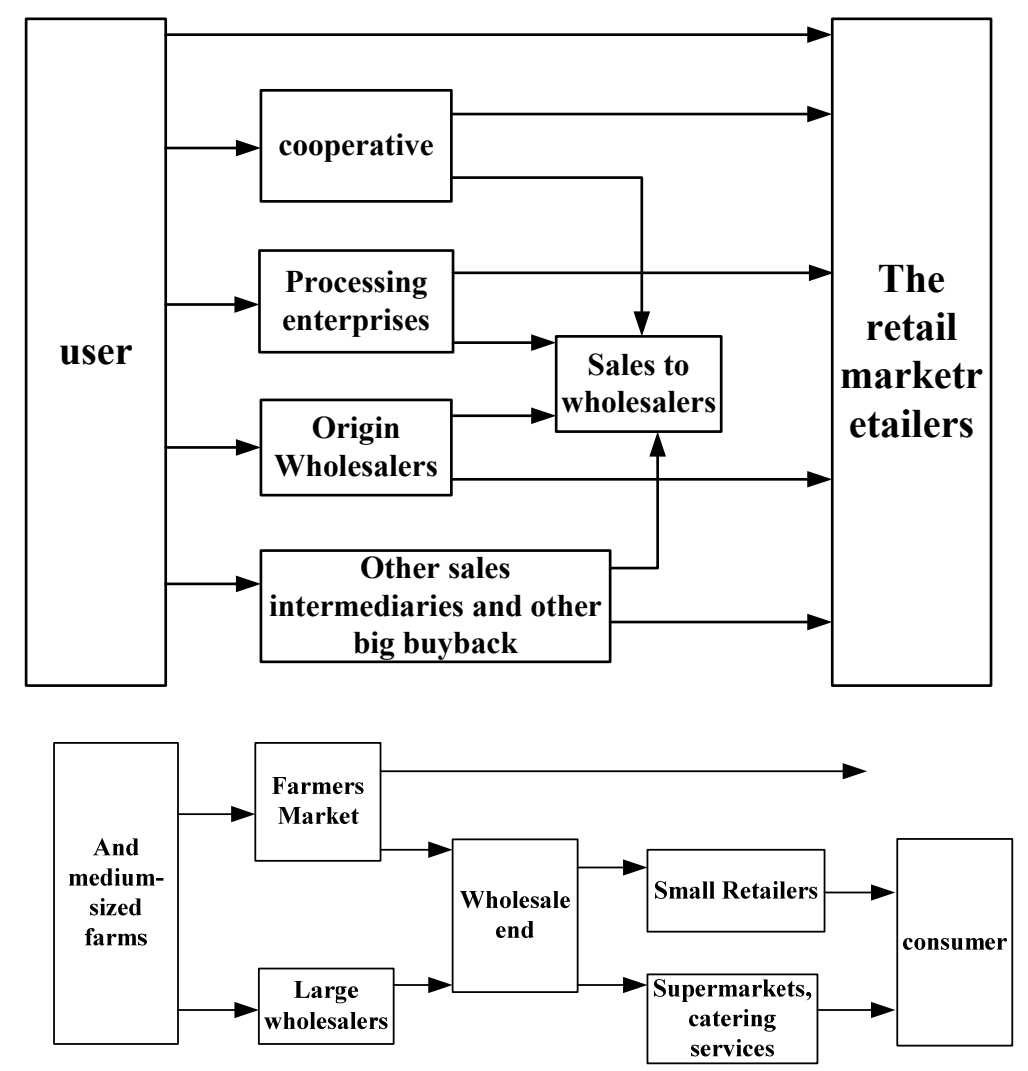

Figure 1.China and the United States made a logistics system compare

Research efforts should focus on practical and realistic above, especially agricultural products logistics technology, such as agricultural supply chain logistics technology, agricultural products cold chain logistics technology, logistics and safety of agricultural technology, agricultural logistics and information technology and so on. Because there is a huge regional differences in our country, so the logistics of agricultural products compatible with the theoretical framework of logistics model also need to follow to create different geographical features. 


\subsection{Modern logistics technology}

For operators of agricultural products through modern agricultural logistics mode can save transaction costs, increase product sales profits, shorten the operating cycle; for consumers, can be more immediate benefits, not only to speed up the flow of agricultural products, but also to enjoy a high level service. In modern agricultural logistics system construction, depending on the characteristics of agricultural products, logistics means different functional, modern logistics technology can be broadly classified was shown in Figure 2:

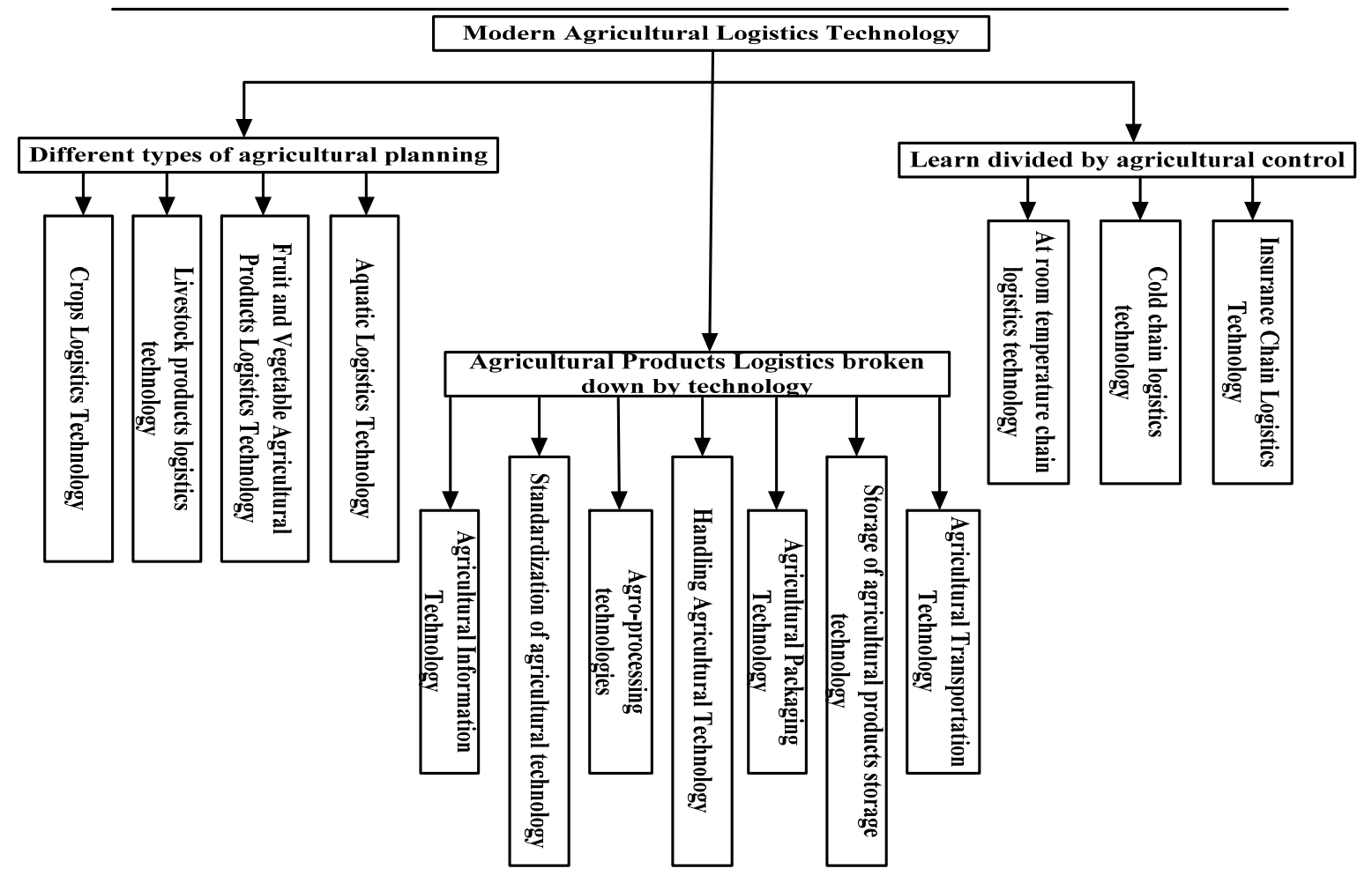

Figure 2. Modern logistics technology classified

To a solid foundation logistics system, it is necessary entity system and information network system construction is good, they are composed of basic elements of the logistics system. Solid material foundation upon which to build the system: road construction, railway construction, construction of inland shipping. They make up the carrier transport logistics system, focus on the construction of the system is to provide physical protection of the material basis for the development of fast and efficient transport. Information network construction, speed up the construction of information network platform and logistics related to agriculture, it is necessary to build an integrated information platform for agricultural product logistics, the integration of agricultural origin, agricultural products processing enterprises, agricultural products distribution center, the integration of all the advantages, storage and transportation and handling by distribution business as linked bonds.

\section{Traceability system to ensure food safety}

Traceability is the safety of agricultural products: in the event of health hazards found, in accordance with the listing from raw materials to finished final consumption process, all aspects of all information must be recorded retroactively flows, reclaim unused consumer goods, withdraw marketing authorization and other activities to reach cut off the source, eliminate the hazard, the purpose of reducing the loss of such a query feature from the consumer to the origin of the called traceability. Namely the establishment of cover agricultural products (food) from primary products to the final consumer goods at all stages of the data repository, so if it is found agricultural (food) quality problems can immediately find what went wrong, who is out of the question. This is conducive to 
control agricultural (food) quality, and timely and effective treatment quality issues, accountability, and ultimately improve the level of safety.Quality and safety of agricultural products traceability system was shown in Figure 3:

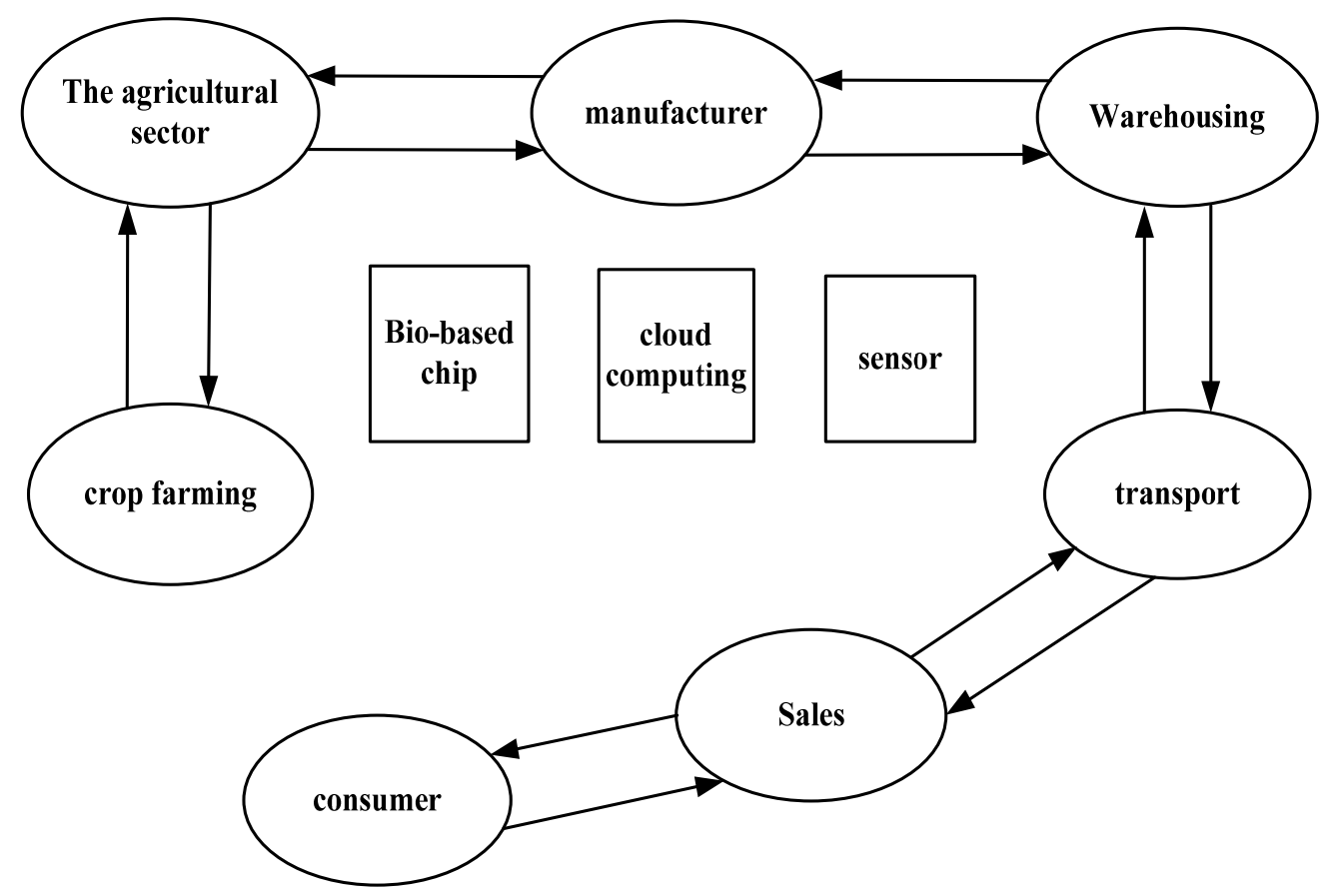

Figure 3. Quality and safety of agricultural products traceability system

For divided into different areas of information technology means that we can use, including the establishment of agricultural production, processing, distribution and safety supervision and inspection of the whole process, early warning control information such as recording, transmission and management. Our agricultural products and agricultural industry in order to obtain sufficient competitiveness in international markets, the quality and safety is a top priority, but it is more substance to protect the masses basic life. A full two-way traceability systems query system, "from the farms to the table", "from the table to the field," as long as the situation appeared to violate the requirements of the product occurs, the system will be able to immediately find the cause of the problem and take appropriate remedial measures spin. The establishment of agricultural supply chain tracking, traceability system completely in favor of the quality of agricultural management, not only can immediately trace the source of the harm, but also can effectively control the degree of risk, and be able to recycle the offending products and timely, risk to a minimum level.

\section{Conclusions}

In this paper, a review of a large number of domestic and foreign research literature on agricultural development status of e-commerce at home and abroad were analyzed and compared; combed agricultural development in e-commerce course; summarize the e-commerce in China's major agricultural business model using the Fifth; summed up China's agricultural e-commerce made in the presence of the main problems and their causes, such as: many obstacles in our rural areas to promote agricultural e-commerce restrictions imposed, agricultural e-commerce services facing agricultural e-commerce logistics links encountered some bottlenecks, any natural agricultural food safety is a prominent problem to be solved; also proposed to solve the above problems related suggestions, such as: how to actively guide farmers voluntarily to put up the construction of agricultural e-commerce systems, how to establish a sound system service system, how to accelerate the construction of agricultural infrastructure of logistics, how to establish and improve agricultural standardization system specification and traceability systems. 


\section{References}

[1] Qu B, Jing X, Wang X, et al. Design on cucumber traceability system based on the internet of things[M]//Computer and Computing Technologies in Agriculture V. Springer Berlin Heidelberg, 2012: 199-208.

[2] $\mathrm{Xu} \mathrm{H}$, Zhang R, Lin C, et al. Using RFID technology to development of agricultural products quality safety traceability system on Internet of things[J]. Journal of Chemical \& Pharmaceutical Research, 2014, 6(10).

[3] Yan B, Shi P, Huang G. Development of traceability system of aquatic foods supply chain based on RFID and EPC internet of things[J]. Transactions of the Chinese Society of Agricultural Engineering, 2013, 29(15): 172-183.

[4] Yan B, Hu D, Shi P. A traceable platform of aquatic foods supply chain based on RFID and EPC Internet of Things[J]. International Journal of RF Technologies: Research and Applications, 2012, 4(1): 55-70.

[5] Liu K. Research on the Food Safety Supply Chain Traceability Management System Base on the Internet of Things[J]. International Journal of Hybrid Information Technology, 2015, 8(6): 25-34.

[6] Zhang X, Wang J, Cui J, et al. Design of Distributed Traceability System for Wheat Products Quality[M]//Computer and Computing Technologies in Agriculture V. Springer Berlin Heidelberg, 2012: 498-507.

[7] Xia X, Qiu Y, Hu L, et al. Application of Information Technology on Traceability System for Agro-Food Quality and Safety[M]//Computer and Computing Technologies in Agriculture VIII. Springer International Publishing, 2015: 257-269.

[8] Liu F, Wang Y, Jia Y, et al. The egg traceability system based on the video capture and wireless networking technology[J]. International Journal of Sensor Networks, 2015, 17(4): 211-216.

[9] Verdouw C N, Robbemond R M, Verwaart T, et al. A reference architecture for IoT-based logistic information systems in agri-food supply chains[J]. Enterprise Information Systems, 2015: $1-25$.

[10]Piromalis D D, Arvanitis K G. Radio frequency identification and wireless sensor networks application domains integration using DASH7 Mode 2 standard in agriculture[J]. International Journal of Sustainable Agricultural Management and Informatics, 2015, 1(2): 178-189.

[11] Yan L. Optimizing suggestions for Gadus morhua supply chain between Norway and China: base on bilateral FTA and product traceability system[J]. 2015.

[12] Serrano M, Quoc H N M, Le Phuoc D, et al. Defining the Stack for Service Delivery Models and Interoperability in the Internet of Things: A Practical Case With OpenIoT-VDK[J]. Selected Areas in Communications, IEEE Journal on, 2015, 33(4): 676-689.

[13]López-Gómez A, Cerdán-Cartagena F, Suardíaz-Muro J, et al. Radiofrequency Identification and Surface Acoustic Wave Technologies for Developing the Food Intelligent Packaging Concept[J]. Food Engineering Reviews, 2015, 7(1): 11-32. 